\title{
INTERNAL CROWDSOURCING AS AN INSTRUMENT OF PERSONNEL INVOLVEMENT
}

\author{
Ruslan DOLZHENKO(D) \\ Department of Labor Economics and Personnel Management, \\ Ural State University of Economics, 8 Marta str., 620144, Ekaterinburg, Russia \\ *E-mail:snurk17@gmail.com
}

\begin{abstract}
Purpose - in the study the opportunities to utilise crowdsourcing as an instrument of personnel involvement are considered. The essence of personnel engagement is analysed; the terms "personnel engagement" and "personnel involvement" are compared.

Research methodology - the case study of JSC "Sberbank", the first Russian company that implemented internal crowdsourcing in its activity, is provided.

Research limitations - the paper considers the case of a large financial company; it is impossible to conclude the applicability of technology in other cases. However, this experience can be recreated by almost any organisation that embraces thousands of workers in its structure

Findings - personnel involvement is understood as a set of measures that forms employees' abiding interest in solving organisational problems and an increased emotional attachment to the organisation's aims and values. The essence of crowdsourcing is defined, its implementation scheme is described, and the classification of crowdsourcing projects is developed. The authors highlight the advantages of the use of internal crowdsourcing, i.e. implemented through the efforts of the company's staff, for the employees and the organisation itself.
\end{abstract}

Practical implications - examples of the application of this technology for resolving organisational issues and involving personnel are offered.

Originality/Value - the article studied the potential of using crowdsourcing in solving business issues.

Keywords: crowdsourcing, internal crowdsourcing, personnel engagement, personnel involvement.

JEL Classification: L24, L29, M19.

Conference topic: Contemporary Organizations Development Management.

\section{Introduction}

The scientific-technological progress leads to considerable shifts in the productivity of employees. However, the exponential growth of social changes does not correspond to the opportunities of people to assimilate them in their lives. Moreover, this particularity is typical of all the aspects of social life, including the sphere of human resource management. Many innovations remain unclaimed because employees cannot find a use for them in their work and they are not motivated to do something new for the sake of the organisation. Thus, before introducing any changes to the system of human resource management, it is necessary to ensure whether the employees are ready for alterations and, if not, prepare them. Studies demonstrate that the best way to do this is to involve personnel in the process of making changes. Internal crowdsourcing is one of the new instruments designed to encourage employees' engagement to the labour activity. The term crowdsourcing dates back to 2006 when it was first coined by J. Howe (Howe, 2006), and since then, for a decade now, it has engrossed the minds of theorists and practitioners. Crowdsourcing is primarily regarded as a tool for attracting the public to resolving the company's topical problems (Brabham, 2008). We should bear in mind that the company's staff can be treated as a target audience of crowdsourcing, and in this case, we can talk about a particular variety of this technology. Due to the certain specifics of such activities, it is necessary to analyse opportunities and directions of using internal crowdsourcing to involve employees in the work of the organisation, but first, let us describe this technology and its opportunities in the sphere of personnel management. 


\section{Previous research: crowdsourcing as a new form of labour organisation in a company}

We should note that labour activity, like any other form of human activity, has undergone significant changes in the process of the evolution of society. The division of labour is one of the critical factors in the development of the economy, and as last decades showed, this phenomenon is not static as well. In our opinion, the evolution of the forms of the division of labour can be presented as follows (Figure 1).

$\left.\left.\left.\left.\left.\left.\sum \begin{array}{c}\text { SelfSourcing } \\ \text { Production } \\ \text { in employee's } \\ \text { hands }\end{array}\right\rangle \begin{array}{c}\text { InSourcing } \\ \text { The division of labour, } \\ \text { specialization } \\ \text { within the company }\end{array}\right\rangle\right) \begin{array}{c}\text { OutSourcing } \\ \text { Contracting out of } \\ \text { labour functions } \\ \text { to partner companies }\end{array}\right\rangle\right\rangle \begin{array}{c}\text { CrowdSourcing } \\ \text { Contracting out of } \\ \text { labour functions to } \\ \text { a large group of people }\end{array}\right\rangle$

Figure 1. The evolution of the forms of the division of labour (source: Dolzhenko \& Lobova, 2015)

As Figure 1 illustrates, each stage carries a name with the root sourcing (the transfer of resources): from selfsourcing (sole production, when all production is concentrated in the hands of one individual), through insourcing (the division of labour within the organization) and outsourcing (transferring a number of labour functions to external specialized companies) to crowdsourcing (the transfer of some labour functions to a large group of people in the form of public offer). From our viewpoint, this is crowdsourcing that represents one of the newest and the most progressive forms of labour implementation in modern society. We should specify that it can be unambiguously attributed to neither labour nor entrepreneurial relations. This is a unique hybrid mix of civil, labour, contractual and partnership relations.

Crowdsourcing is, therefore, a particular type of meta-labour relations. Jeff Howe introduced the term crowdsourcing. He defined crowdsourcing as the act of a company or institution taking a function once performed by employees and outsourcing it to an undefined (and generally large) network of people in the form of an open call. The crucial prerequisite is the use of the open call format and the large network of potential labourers (Howe, 2012).

Over the past ten years, crowdsourcing has gained importance, and the number of scientific publications addressing crowdsourcing has increased. When considering the most cited published literature on crowdsourcing use, two publications should be noted. The first is the publication of Enrique Estellés-Arolas and Fernando González-Ladrónde-Guevara, in which the authors obtain "an exhaustive and global definition to describe any given crowdsourcing activity" (Estellés-Arolas \& González-Ladrón-de-Guevara, 2012); and the second is the paper by Brabham that describes the potential of using crowds to solve problems (Brabham, 2008).

Due to multiple opportunities for application, many human and social sciences - from psychology, philology and culture to economics, sociology, political science and law, study crowdsourcing. Of all the publications addressing crowdsourcing, it is important to highlight those that describe enterprise crowdsourcing. The most widespread applications of the practice in companies are:

- processing of scanned documents for companies (Karnin, Walach, \& Drory, 2010);

- IT inventory management (Vukovic, 2009);

- Marketplaces for enterprise support services (Lopez, Vukovic, \& Laredo, 2010)

- Crowdsourcing for a distributed problem solving (Soliman \& Tuunainen, 2015);

- sites for end-user support (Goncalves, Hosio, Vukovic, \& Konomi, 2017);

- interested customers integration (La Vecchia \& Cisternino, 2010), etc.

I. D. Kotlyarov studies how the use of crowdsourcing in a company influences labour relations and alienation of labour, in particular (Kotlyarov, 2015). In the context of the present paper, it is necessary to determine the crowdsourcing application sphere from the standpoint of an organisation. In this case, it can be defined as the use of intellect and experience of a large group of customers, employees and members of the public for producing new ideas to improve products, processes, services and (or) for carrying out an appraisal of essential decisions and documents of the organisation.

The central purpose of the paper is to study internal crowdsourcing, which is implemented by the staff of an organisation. What are the benefits an organisation gets in case of using it? First, thanks to internal crowdsourcing, every employee has an opportunity to influence the processes and decisions taken within the company. Second, it helps to reach the right decision or reduces the possibility of making a wrong one and, therefore, saves time and money as the aggregated knowledge and experience of all participants are incomparably superior to those of an expert of a working group (Raykar et al., 2010). Also, third, when using crowdsourcing, a company accelerates transformation processes significantly since they directly depend on the engagement of employees and clients to the process of changes. Thus, the use of crowdsourcing in a company can exert an immediate effect on the degree of employees' engagement so that is why the crowdsourcing can be a new business model of human resources management (Marjanovic, Fry, \& Chataway, 2012).

Let us discuss, what engagement of personnel means and in which way the use of crowdsourcing can influence the company. First of all, it is necessary to draw a distinct line between the two terms - engagement of personnel and involvement of personnel. In the practice of human resource management, the involvement of personnel is a set of 
measures aimed at involving employees in the process of the company's governance by giving them powers to impact the decisions and actions concerning their work. In other words, it describes the external aspect of the impact of an organisation on its staff and may result in a response in the form of creation of stable behavioural attitudes among employees and an increase of personnel's engagement. Engagement of employees, in turn, reflects the proper attitude of the staff towards the organisation. From the authors' point of view, engagement of personnel is a steady attitude of employees implying their constant concentration on handling the tasks which produce the additional effect for the organisation. This attitude is manifested in additional emotional attachment of employees to the purposes and values of the organisation.

According to S. Verba, engagement of personnel is primarily a predisposition of an individual to participate in one or another labour activity, which consists of three components - knowledge, interest and performance (Verba, Kay, \& Henry, 1995). Employee's expertise and knowledge of the work, combined with a desire to understand the trends, stay abreast of innovations and deliver impressive performance form their engagement.

The concept of employee engagement of Gallup Research Institute is one of the most well-known approaches to evaluation and management of staff engagement. It involves the use of Q12 questionnaire ("The Gallup Workplace Audit" or GWA) embracing twelve statements. The approach of talents maximisation forms the basis of this questionnaire, according to which:

Per-person productivity $=$ Talent $*$ (Relationship + Right Expectation + Recognition $/$ Reward $)$. Each statement of Q12 questionnaire covers a number of factors influencing the overall level of employee engagement (Figure 2).

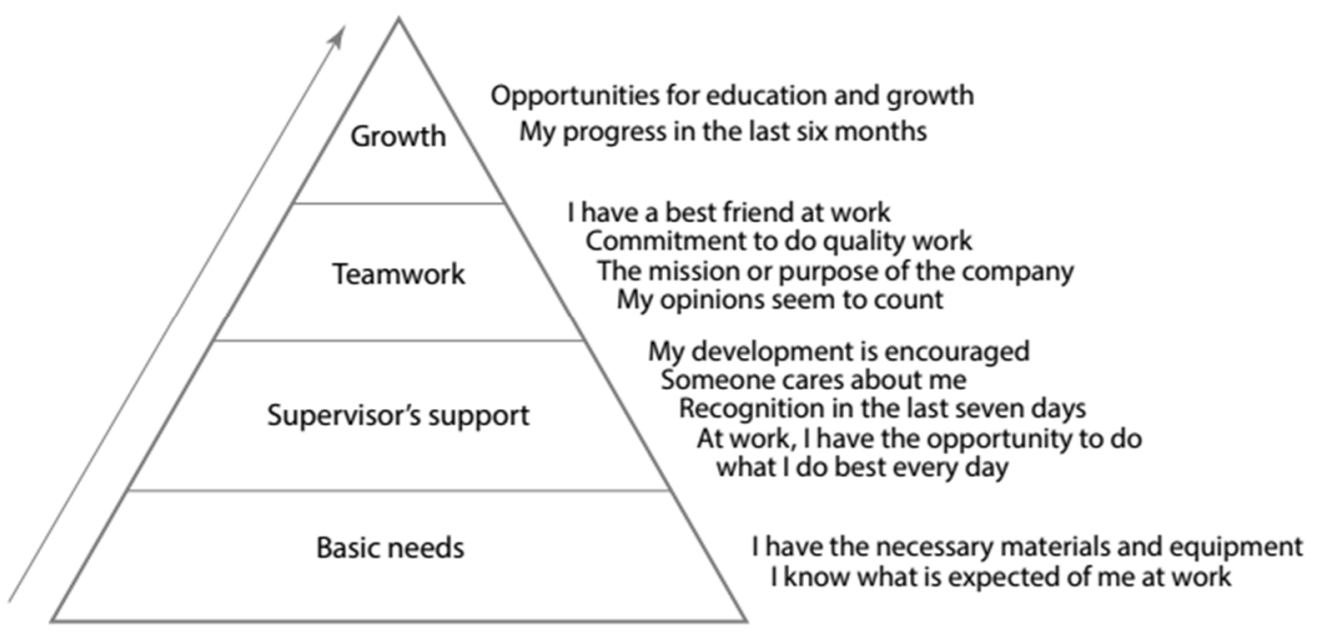

Figure 2. Factors influencing employee engagement according to Gallup methodology (source: author's work)

The more obvious these factors in the work of employees, the stronger their engagement in the company's labour activity. Moreover, scientific studies demonstrate that if an organisation provides favourable conditions for its staff to implement their professional skills and abilities, increases autonomy of its workers, uses the feedback system, etc., then personnel engagement will increase (Lin \& Hsieh, 2002). Crowdsourcing helps fulfil these conditions for enhancing personnel engagement. Thus, we can argue that internal crowdsourcing is a tool, which enables a company to involve its personnel in the implemented changes. We should specify that, on the one hand, participation in crowdsourcing activity does generate engagement of personnel, but, on the other hand, crowdsourcing projects are primarily joint by employees who are already absorbed by their work. It means that crowdsourcing is a tool of both the formation and implementation of engagement. Thus, taking part in crowdsourcing increases the attractiveness of the company in the eyes of the staff and enables employees to utilise their talents for improving production processes and realise their contribution to the changes that take place in the company. Unfortunately, at the moment not many Russian companies are involved in the practice of crowdsourcing. However, one of them, namely Sberbank, has fully implemented this form of relations in its organisational processes. Let us discover the way, in which this organisation applies internal crowdsourcing in order to resolve organisational problems and engage its employees.

\section{Research: Experience in the use of internal crowdsourcing for engaging personnel in the company's labour activity}

Sberbank being the large bank with ambitious short-term objectives pays enormous attention to the development of its personnel. Nowadays, Sberbank is the largest financial institution in Central and Eastern Europe, serving 137 million individual customers, more than 1.4 million corporate customers and having more than 330 thousand employees.

The authors used the case study to analyse the experience of the Sberbank. According to Robert K. Yin, the case study is defined as "an empirical inquiry that investigates a contemporary phenomenon within its real-life context; 
when boundaries between phenomenon and context are not evident; and in which multiple sources of evidence are used" (Yin, 1994).

The case study method allows researchers to investigate the data within a particular context. Using the case study researchers explore and review different situations through detailed contextual analysis of a fixed number of events and conditions, and their relationships. It should be noted that different variants of the case study method are used. We chose the descriptive case study method for our study, as it aims to describe the event, situation, and its causes in detail.

The object of our study is Sberbank. The purpose of the present study is to analyse the Sberbank experience of using crowdsourcing in current activities. To analyse this experience the following conceptual schema was used (Figure 3).

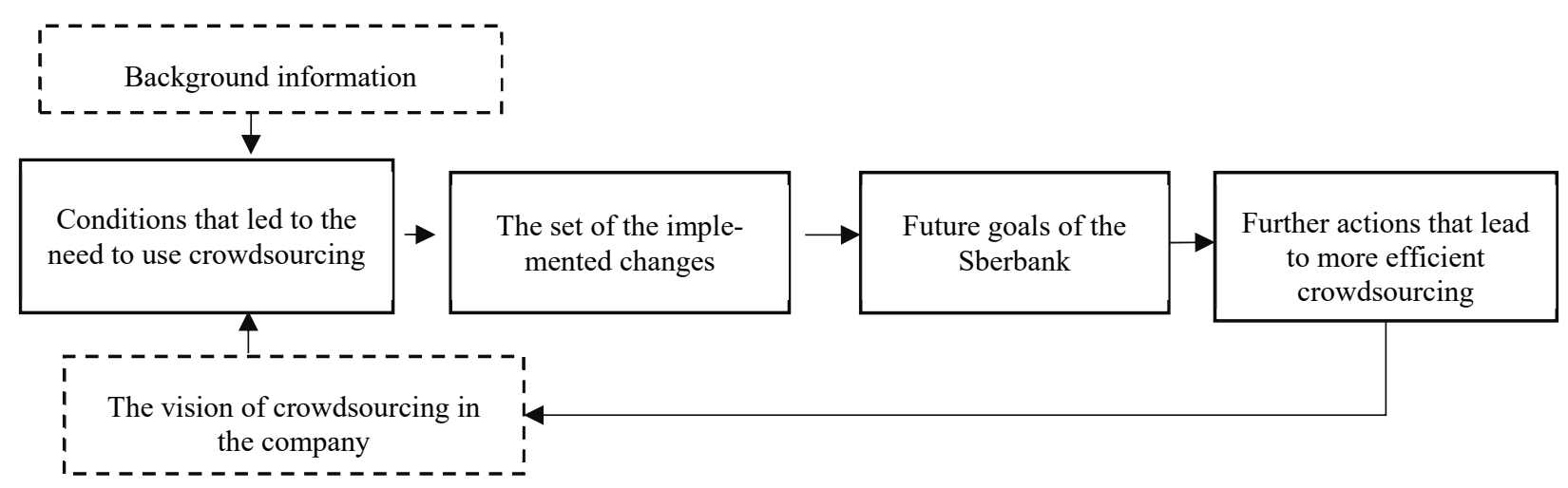

Figure 3. The conceptual schema of analysing the crowdsourcing in the Sberbank (source: author's work)

At the first stage of the present study, we analysed the conditions that led to the beginning of using the crowdsourcing in the Sberbank. At the second stage of the study, we analysed the changes already implemented by the crowdsourcing (What has been done?); we defined its goals in the Sberbank (What is the vision of the Sberbank?) and the steps to be taken (What has to be done in future?). The present study considers 6 years covering 2012-2019 and starting with the beginning of use the crowdsourcing in the Sberbank in 2012, as well as the expected status of this technology in 2019. The study was based on the company data and the interaction with the managers involved in the crowdsourcing.

Several years ago, Sberbank adopted many innovations in its practice that scarcely have any analogues in Russian and foreign practices. Here, we are referring to the development of crowdsourcing by a credit organisation. The management of the bank planned to involve 250 thousand administrators and other employees in the process of changes and effectively use their intellect and experience. In this case, the size should become the bank's asset. In just a few years, the system of internal crowdsourcing was established in the company.

At the moment, it is built on three essential foundations: methodology, infrastructure and instruments of personnel involvement. Let us consider their content in detail. We will start by discussing the crowdsourcing methodology in the bank. It incorporates a range of documents regulating crowdsourcing activity in the company. In the first place, this is a technological scheme of crowdsourcing organisation which determines the roles of all the participants and the principles of their interaction. Moreover, crowdsourcing is obligatory when developing an internal document of the bank, i.e. employees can influence the content of those provisions and regulations which they will have to carry out in the future. Moreover, every regional branch of Sberbank has a division in its structure that is responsible for the organisation of crowdsourcing in the subordinate offices and involvement of the staff to the topical projects.

The next important aspect of crowdsourcing which guarantees its effectiveness is a specialised infrastructure, represented by the respective platforms. The specially designed online medium idea.sberbank21.ru serves as an ITplatform for internal crowdsourcing. Only Sberbank's employees have access to this website and only from external computers (not from Sberbank's computer network). This website is moderated and, besides, the system allows the users to adjust its interface to every ordering customer such as business departments of the bank (retail unit, corporate unit, etc.). Finally, without the appropriate system of personnel involvement, application of crowdsourcing in the banking sphere would be impossible. In Sberbank, there is a practice of reading the major books on management and economics by its workers. Every month a new book is published by Sberbank's publishing house and distributed among the employees of all departments to familiarise themselves with its content. In late 2011, such books as "Crowdsourcing..." (Howe, 2012), "Wikinomics..." (Tapscott \& Williams, 2009), "Wiki-Government..." (Novek, 2012) were consequently published. They were needed to prepare the personnel for those changes they will have to face in their activity, and begin to utilise crowdsourcing actively.

Moreover, top-management of the bank issued personal appeals to the workers and organised the feedback system. The company emphasises that involvement of the personnel in crowdsourcing projects on urgent issues for Sberbank is provided, primarily, by personal engagement of the staff, but not by administrative measures.

Talking about the utilisation of crowdsourcing for the needs of the Sberbank, there exist various types of this technology (Figure 4). 


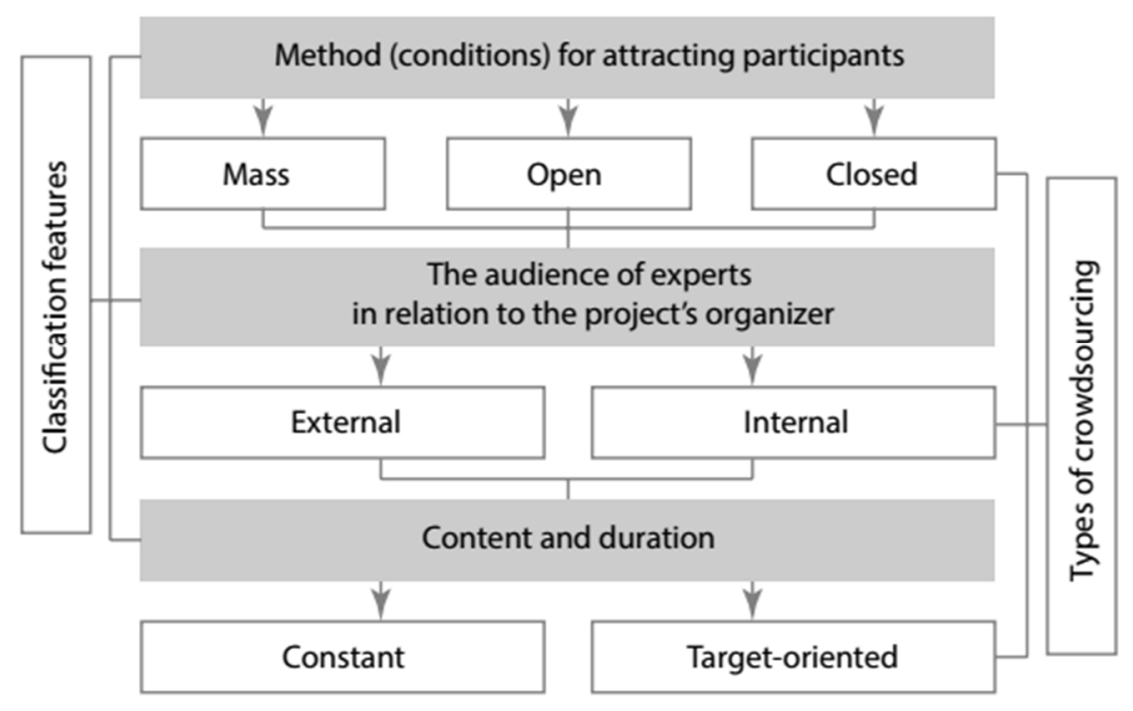

Figure 4. Types of crowdsourcing by various classification features (source: author's work)

The organisation offers financial benefits to the best contributors to crowdsourcing projects. For employees, there is also an opportunity to demonstrate their professional qualities during the discussion (in order to earn a possible promotion). Nowadays Sberbank uses three scenarios of crowdsourcing projects. Their characteristics are illustrated in Figure 5.

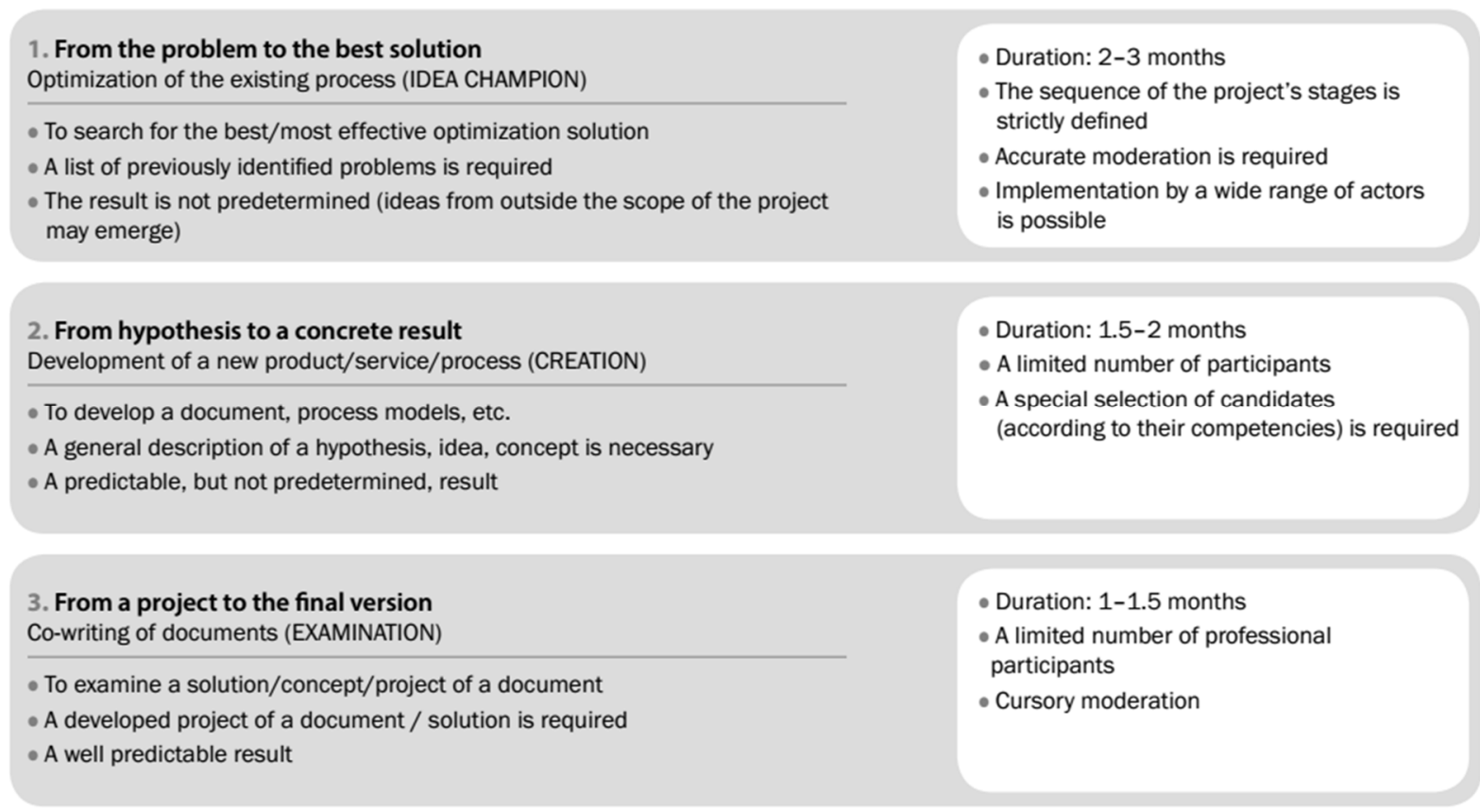

Figure 5. The types of crowdsourcing projects used in Sberbank (source: author's work) ble 1.

Approximate costs for the full implementation of the crowdsourcing project in the organisation are given in Ta-

Table 1. Costs for project implementation in the framework of internal crowdsourcing (source: author's work)

\begin{tabular}{|c|c|c|c|}
\hline \multirow{2}{*}{ Services } & \multicolumn{3}{|c|}{ Types of projects of internal crowdsourcing } \\
\hline & Type 1 & Type 2 & Type 3 \\
\hline IT platform (per year) & \multicolumn{2}{|c|}{$\$ 787$ ths. } & $\$ 35$ ths. \\
\hline Technical and organisational support + methodology & \multicolumn{2}{|c|}{$\$ 150$ ths. (per project) } & $\$ 35$ ths. (per month) \\
\hline Total & \multicolumn{2}{|c|}{$\begin{array}{c}\$ 3.65 \text { mln. } \\
(18 \text { projects per years })\end{array}$} & $\begin{array}{c}\$ 450 \text { ths. } \\
\text { (number of projects is not limited) }\end{array}$ \\
\hline
\end{tabular}


Cost for the system support including the managers' salary is also given in Table 2 concerning crowdsourcing projects implemented on the third party platforms of partner-companies.

Salary costs for the specialists responsible for the implementation of crowdsourcing in Sberbank can be neglected because this activity is a part of their standard functionality which includes a range of work within the corporate innovation system of the bank.

As practice shows, dealing with an organisation's documents is the best sphere for crowdsourcing. In the second half of 2013, the bank introduced a compulsory examination of all critical documents stipulating the effective policy and the rules of interaction with regional divisions. During the first four months, more than 9.000 proposals were received. The authors of the documents accepted a quarter of them. The examples of the documents that were discussed by the crowdsourcing community are presented in Table 2.

Table 2. The examples of crowdsourcing of regulatory documents (source: author's work)

\begin{tabular}{|c|c|}
\hline Examples of the documents & The results of crowdsourcing \\
\hline $\begin{array}{l}\text { The standards of service for individuals in the } \\
\text { bank's branches }\end{array}$ & $\begin{array}{l}\text { Scripts and tactics of service are corrected, tasks are elaborated, the best } \\
\text { practices are taken into account }\end{array}$ \\
\hline Performance of terminals and ATMs & $\begin{array}{l}\text { Control over servicing organisations is specified, the functions of servicing } \\
\text { units are balanced }\end{array}$ \\
\hline A set of credit products for small businesses & Additional opportunities for refinancing credits of other banks are offered \\
\hline
\end{tabular}

This direction of crowdsourcing application can be implemented in any Russian organisation. For this purpose, it is necessary to meet the following requirements:

this technology should be built into organisational processes, the company's management should support the idea to use crowdsourcing and, finally, there should be a system of engaging personnel in such activities.

According to the bank's top management, the most effective implementation of crowdsourcing was achieved in 2013, when a significant part of the bank's staff was involved in the examination and improvement of the organisation's strategy (the project Sberbank's Strategy for the period 2014-2018). The task to involve the employees scattered across Russia (over 200,000 people) and working in different departments was performed using crowdsourcing. Ideas and comments of the employees exerted a substantial influence of the content of the Strategy, which will be implemented by them during the period 2014-2018.

"The Book of the Values of Sberbank" is one of the latest large-scale crowdsourcing projects on personnel engagement. Its principal objectives were gathering materials for "The Book of the Values of Sberbank" (a document which was later distributed among the employees), familiarizing them with the banks new principles adopted along with the new Strategy of the bank for the period 2014-2018, collecting information on how well the staff understand the new values. This project was held for 2 months. The employees were asked to name this document, formulate interpretations for the values of the bank, consolidate a set of simple and clear rules of conduct in the workplace following the organisational standards. The details on the quantitative results of this project are provided in Figure 6.

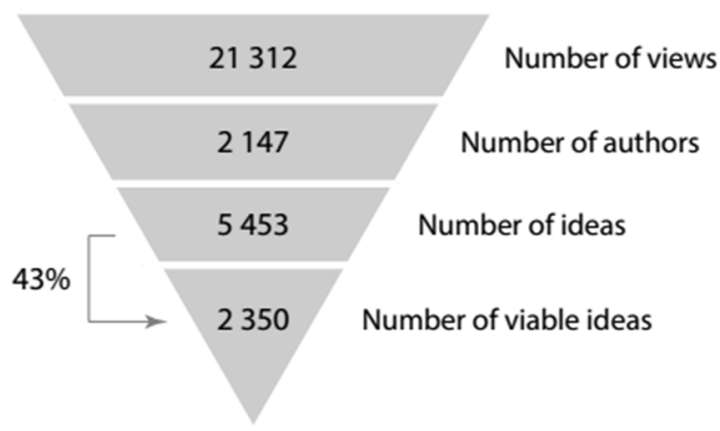

Figure 6. The results of internal crowdsourcing of the project Sberbank on

"The Book of the Values of Sberbank" (source: author's work)

To sum up the results of the current crowdsourcing activity in Sberbank, we can conclude that this organisation is a leader in the use of crowdsourcing in Russia. To be precise, the achievements of the organisations embrace the following.

From 2009 to the present day, the employees of the bank have submitted 230.000 proposals for improvement of the company's activity. The entire personnel of the company (more than 230.000 workers) have access to the crowdsourcing sites, and 95.000 of them annually participate in crowdsourcing projects (approximately $41 \%$ of the total number of employees). 
The key purpose of crowdsourcing in the bank is the optimisation of business and supporting processes. The overall effect of the optimisation in Sberbank during the period of crowdsourcing application made up 60 billion rubles, 13.9 billion of this sum is the result of the implementation of the initiatives submitted on crowdsourcing sites.

In total, 120 projects with staff participation were held on the internal crowdsourcing site of the bank. Besides, more than 100 examinations of the internal documents were conducted (10.000 (25\%) out of 40.000 ideas submitted to discuss the documents were approved). The total number of 30 web surveys were carried out in SurveyMonkey for the fundamental blocks (retail block, corporate block, HR block).

This was the experience of Sberbank in implementing crowdsourcing projects designed to get on well with organisational tasks and employee involvement. These examples, if adapted, can be used by other companies, which investigate the possibilities to utilise additional reserves to improve their performance.

\section{Discussion of recommendations for the development of crowdsourcing practices in Sberbank}

The analysis of the practical use of crowdsourcing in this organisation allowed identification of some problems that reduce its effectiveness. Some of them are the following:

1. Ineffective gathering of ideas: a large number of incoming ideas, their low quality. 86000 ideas were registered during the crowdsourcing of Sberbank, $20 \%$ of them are under consideration.

2. Ineffective selection and approval procedures: $100 \%$ of ideas need to be examined, long examination periods, high labour costs, the ineffective procedure of "filtration". $52 \%$ of ideas were rejected, only $10 \%$ of ideas were considered in time in Sberbank among 10400 ideas approved for the implementation.

3. Inefficient use of crowdsourcing platforms: low interest in business, the dissatisfaction of employees. 7500 ideas were implemented by Sberbank, $80 \%$ of them were under consideration for more than 1 year.

New approaches of selecting and evaluating the ideas are necessary in order to improve the working models qualitatively with ideas in the framework of crowdsourcing:

- Business and/or customers should set a problem for solving;

- Work on solutions should be organised in teams;

- New principles of motivation for the authors of ideas should be well-organised - conversion from participant's motivation to the team's motivation;

- Expert professional community should be formed according to types of activities;

- Effective communication should be provided between the participants while searching for the solution;

- The community's participants should perform a selection of ideas;

- "Filtration" of ideas should be performed using rating (with the help of participants' voting);

- Efforts should be concentrated on the best solutions;

- The number of active participants should be maximum.

The practice of crowdsourcing using in Sberbank shows that the following elements are necessary to build an effective crowdsourcing platform: the Internet platform, rating system of the participants and their suggestions, "filtration" of the participants before including into the project, "filtration" of the suggestions in order to find spam (criteria of inefficient operation), off-topic discussions, guide for the beginners of crowdsourcing, system for setting up (a) problem(s) for the participants, remuneration system for the project leaders, system of project results reporting, facilitators work on the platform, organized security system and privacy of content, retrieval system of suggestions according to different criteria, etc.

The comparison of the results of a number of crowdsourcing projects of Sberbank leads to the conclusion that the activity of crowdsourcing participants largely depends on the topic of the problem and participants' involvement in this process. The more popular it is among the participants, the more significant results will be achieved on the platform. Similar studies of foreign researches showed that there is no correlation between the quality of crowdsourcing and remuneration system for participants (Yuen, King, \& Leung, 2011). Additional remuneration for those wishing to work within the framework of crowdsourcing leads to an increase in the number of participants but does not increase the quality of their suggestions.

\section{Conclusions}

The main object of study of this article is internal crowdsourcing, which is implemented by a company's personnel. The opportunities to use it are simple, but crowdsourcing is primarily an instrument of employee involvement in labour activity. Moreover, through the use of internal crowdsourcing companies can improve their performance, involve their staff to the process of changes, establish the culture of effective cooperation of all participants of labour relations.

This experience was implemented by the largest Russian bank - JSC "Sberbank of Russia". The company used its size as an advantage. Applying to crowdsource, it managed to involve its personnel in the process of solving of topical problems. However, this experience can be recreated by almost any organisation that embraces thousands of workers in its structure, whose hidden potential is still undiscovered. 
This article studied the potential of using crowdsourcing in solving business issues. On the one hand, this potential is enormous, and crowdsourcing which is successfully utilised in many countries worldwide is slowly gaining popularity in Russia; on the other hand, high costs and the lack of necessary skills limit the prospects of using crowdsourcing in business practice.

\section{Disclosure statement}

The author declares that he has not any competing financial, professional, or personal interests from other parties.

\section{References}

Brabham, D. C. (2008). Crowdsourcing as a model for problem-solving: An introduction and cases. Convergence, 14(1), 75-90. https://doi.org/10.1177/1354856507084420

Dolzhenko, R. A., \& Lobova, S. V. (2015). Internal crowdsourcing projects in the company: organization and realization. International Business Management, 9(1), 145-150.

Estellés-Arolas, E., \& González-Ladrón-de-Guevara, F. (2012). Towards an integrated crowdsourcing definition. Journal of Information Science, 38, 189-200. https://doi.org/10.1177/0165551512437638

Goncalves, J., Hosio, S., Vukovic, M., \& Konomi, S. (2017). Mobile and situated crowdsourcing. International Journal of Human Computer Studies, 102, 1-3. https://doi.org/10.1016/j.ijhcs.2016.12.001

Howe, J. (2006). The rise of crowdsourcing. Wired Magazine. Retrieved from https://www.wired.com/2006/06/crowds/

Howe, J. (2012). Crowdsourcing: Why the power of the crowd is driving the future of business. Moscow: Al'pina Publisher.

Yin, R. K. (1994). Case-study research design and methods. Thousand Oaks, London: Sage.

Yuen, M. C., King, I., \& Leung, K. S. (2011). A survey of crowdsourcing systems. In Privacy, Security, Risk and Trust (PASSAT) and 2011 IEEE Third International Conference on Social Computing (SocialCom), Boston, MA, USA (pp. 766-773). IEEE. https://doi.org/10.1109/PASSAT/SocialCom.2011.203

Karnin, E., Walach, E., \& Drory, T. (2010). Crowdsourcing in the document processing practice. In F. Daniel, \& F. M. Facca (Eds.), ICWE 2010: Current Trends in Web Engineering. Lecture Notes in Computer Science (Vol. 6385). Berlin, Heidelberg: Springer. https://doi.org/10.1007/978-3-642-16985-4_36

Kotlyarov, I. D. (2015). [Internal crowdsourcing: an attempt of a political-economic analysis]. Mnogourovnevoe obshchestvennoe vosproizvodstvo: voprosy teorii i praktiki [Multilevel social reproduction: The issues of theory and practice]. Ivanovo: Ivanono State University.

La Vecchia, G., \& Cisternino, A. (2010). Collaborative workforce, business process crowdsourcing as an alternative of BPO. Paper presented at the Proceedings of First Enterprise Crowdsourcing Workshop in conjunction with ICWE. https://doi.org/10.1007/978-3-642-16985-4_40

Lin, S. L., \& Hsieh, A. T. (2002). Constraints of task identity on organizational commitment. International Journal of Manpower, 23(2), 151-165. https://doi.org/10.1108/01437720210428405

Lopez, M., Vukovic, M., \& Laredo, J. (2010, July). PeopleCloud service for enterprise crowdsourcing. Paper presented at the International Conference on Services Computing. Miami, Florida. https://doi.org/10.1109/SCC.2010.74

Marjanovic, S., Fry, C., \& Chataway, J. (2012). Crowdsourcing-based business models: In search of evidence for innovation 2.0. Science and Public Policy, 39(3), 318-332. https://doi.org/10.1093/scipol/scs009

Novek, B. (2012). Wiki-Government. How technologies can make the power better, democracy stronger, and citizens more powerful. Moscow: Al'pina Publisher.

Raykar, V. C., Yu, S., Zhao, L. H., Valadez, G. H., Florin, C., Bogoni, L., \& Moy, L. (2010). Learning from crowds. The Journal of Machine Learning Research, 11, 1297-1322.

Soliman, W., \& Tuunainen, V. K. (2015). Understanding continued use of crowdsourcing systems: An interpretive study. Journal of Theoretical and Applied Electronic Commerce Research, 10(1), 1-18. https://doi.org/10.4067/S0718-18762015000100002

Tapscott, D., \& Williams, A. (2009). Wikinomics: how mass collaboration changes everything. Moscow: Best Business Books.

Verba, S., Kay, S., \& Henry, E. (1995). Voice and equality: civic voluntarism in American politics. Cambridge: Harvard University Press.

Vukovic, M. (2009). Crowdsourcing for enterprises. International workshop on cloud services. Paper presented at the conjunction with 7th IEEE International Conference on Web Services. https://doi.org/10.1109/SERVICES-I.2009.56 